\title{
Erratum to: Phase I trial of verubulin (MPC-6827) plus carboplatin in patients with relapsed glioblastoma multiforme
}

\author{
Kenneth F. Grossmann - Howard Colman • Wallace A. Akerley • \\ Michael Glantz - Yuko Matsuoko - Andrew P. Beelen • Margaret Yu • \\ John F. De Groot • Robert D. Aiken · Jeffrey J. Olson • Brent A. Evans • \\ Randy L. Jensen
}

Published online: 23 March 2013

(C) Springer Science+Business Media New York 2013

\section{Erratum to: J Neurooncol (2012) 110:257-264}

DOI 10.1007/s11060-012-0964-7

There were typographic errors in the name of author Jeffrey J. Olson. The name is correctly spelled in this erratum.

The online version of the original article can be found under doi:10.1007/s11060-012-0964-7.

K. F. Grossmann - W. A. Akerley

Division of Oncology, Huntsman Cancer Institute,

University of Utah, 2000 Circle of Hope Drive,

Salt Lake City, UT 84112, USA

H. Colman · Y. Matsuoko

Department of Neurosurgery, Huntsman Cancer Institute,

University of Utah, 2000 Circle of Hope Drive,

Salt Lake City, UT 84112, USA

M. Glantz

Department of Neurosurgery, Penn State College of Medicine, Hershey Medical Center, Hershey, PA 17033, USA

\section{A. P. Beelen}

Department of Clinical Research, Myrexis, Inc, 305 Chipeta Way, Salt Lake City, UT 84108, USA

M. Yu

Janssen Research and Development, 10990 Wilshire Blvd,

Suite 1200, Los Angeles, CA 90024, USA

\section{J. F. De Groot}

Department of Neuro-Oncology, The University of Texas MD Anderson Cancer Center, 1515 Holcombe Blvd., Unit 431,

Houston, TX 77030, USA

\section{R. D. Aiken}

Department of Neuroscience, Neurosurgery, Medical Oncology, Radiation Oncology, Division of Neurological Oncology, Rush University Medical Center, Chicago, IL 60612, USA

\section{J. J. Olson}

Translational Neuro-oncology Laboratory, Department of Neurological Surgery, The Emory Clinic, 1365-B Clifton Rd., NE, Ste. 2200, Atlanta, GA 30322, USA

\section{B. A. Evans}

Department of Biostatistics, Myrexis, Inc, 305 Chipeta Way, Salt Lake City, UT 84108, USA

\section{R. L. Jensen ( $\square)$}

Departments of Neurosurgery, Radiation Oncology, Oncological Sciences, Huntsman Cancer Institute, Clinical Neuroscience Center, University of Utah, 175 North Medical Drive,

Salt Lake City, UT 84132, USA

e-mail: randy.jensen@hsc.utah.edu 